"Debate" is a new series offering opposing sides of a continuing, controversial issue in tobacco control. In this and the next article, David Hill, director of the Centre for Behavioural Research in Cancer, Anti-Cancer Council of Victoria, Australia and Matthew Myers, executive vice president of the National Center for Tobacco Free Kids in Washington, DC, USA, debate whether tobacco control programmes should be targeted principally at adults or the young. - ED

\title{
Why we should tackle adult smoking first
}

Population-wide tobacco control programmes should aim to reduce teenage and adult smoking. The strategic tobacco control question is about where to put emphasis and how to approach the problem. There are two perspectives from which to argue for an emphasis upon cessation of smoking in adults ahead of prevention of uptake in teenagers: the epidemiology-based and the psychology-based perspectives.

At the tenth world conference on tobacco or health in 1997, Professor Sir Richard Peto used an epidemiological argument that cessation programmes would give the earliest and biggest "dividend" in terms of early reduction of tobacco-related harm. ${ }^{1}$ Even if the exemplar effect of reduced adult smoking prevalence did not indirectly reduce uptake (and I argue that it does), programmes that increase the proportion of adults giving up smoking will restore to non-smoking status many of those who took up smoking as adolescents, probably with minimal tobacco-related health damage. I concede that this approach is not an adequate response to the evidence that tobacco exposure during youth may be more harmful, dose for dose, than it is in later life. ${ }^{2}$ On the other hand, the cessation-first approach is a response that gives added protection to the yet-to-be-born and the recently born from teratogenic, intra-uterine and environmental tobacco smoke (ETS) effects of parental smoking. ${ }^{34}$

From a psychological point of view, I argue that by making cessation-focused programmes most salient, the greatest long-term gains in tobacco control are likely to occur. Salience, of course, does not equate with pervasiveness; any effective tobacco control programme requires pervasive, good-quality background tobaccoeducation programmes in schools. Why? Because it would simply be unethical for the relevant public institutions of a society not to provide timely and tailored education about the largest cause of preventable death faced by its young citizens. Health education about tobacco is justified on moral grounds, regardless of its effect as a deterrent to smoking. And notwithstanding the relatively disappointing long-term results of many school-based trials to reduce uptake, approaches that include social influence aspects and which are supported by community components do make a difference. ${ }^{5}$
Other than high-quality, sustained health education programmes in schools, I argue that programmes and campaigns overtly and exclusively focused on teenagers are problematic for the following reasons.

Theories in developmental psychology suggest that authority messages specific to teenagers are at risk of being rejected by those most at risk of smoking. Adolescence is a period of physiological and psychological change, and of role transition to adulthood, and as such, has a number of distinctive features the health promotion strategist ought to take into account. ${ }^{67}$ Even within the adolescent decade (11-20 years), at least three stages have been identified (11-14, 15-17, 18-20 years): the first concerned with exiting childhood, the second with dominant peer group orientation, and the third with the transition to adulthood.

Attempts to mount persuasive arguments against smoking, based or seen to be based on arguments that it is especially important not to smoke because you are a teenager, or under 18 , or still a dependent, simply invite rejection. Moreover, those adolescents in the greatest hurry to grow up are most likely to be smoking already, having embraced this traditional transition marker, and to be most resistant to authoritative admonitions. At the very least, any message or strategy that will "work" with adolescents must be seen by members of this target group to be treating them as adults.

But of course they are not yet adults. Paradoxically, in mid-adolescence, stereotypical insignia (dress, language, music, appearance, etc) sets them apart, and seems to demand slavish conformity. Well then, if only we could infiltrate this culture, pass off anti-smoking sentiment as a "cool", "trendy" stance. Difficult to do? Many have tried, only to be dismissed as "try-hards".

Another logical and potentially effective approach is to dissociate, or "unhook", smoking from the constellation of risky behaviours to which it is attached: alcohol abuse; precocious, unprotected sex, use of cannabis (and other) illicit substances, and problem behaviour in general. ${ }^{8}$ The first difficulty with this strategy is that it may require us, as tobacco control specialists, to betray our public health colleagues who fight against other behavioural risk factors. I once commissioned a television anti-smoking advertisement about a "tough guy" called "Chopper" who met 
many of the aspirational criteria for teenage male smokers. The besetting problem with this clever advertisement was that its winning, nonsmoker hero was a beer-drinking, bar-room brawler who creates chaos and who walks away whistling nonchalantly as he rejects an offered cigarette.

The fact that the tobacco industry supports, often in the most devious way, teenage campaigns, is an ominous warning signal. It has consistently given sanctimonious public support for restrictions on youth access to tobacco and "It's the law" point-of-sale signage about the legal age to purchase tobacco, at the same time as it uses point-of-sale promotions and merchant incentives to make smoking even more attractive to young people. ${ }^{9}$ Documents discovered as a result of the tobacco settlement in the United States provided a revealing insight into the 1992 corporate communication strategy of Philip Morris (Australia) which planned to "get politicians to 'force' action on the industry, via a youth non-smoking campaign". ${ }^{10}$ Evidently, Philip Morris was confident that youth campaigns could do them little damage. The recent Philip Morris "anti-smoking" teenage campaign on American television is at best ineffective, and possibly counter-productive from a tobacco control point of view. ${ }^{11}$

Implicitly or explicitly, most health promotion includes a strong element of risk communication. I have argued elsewhere that the public health professional's justifiable focus on population risk and risk reduction may intrude into the way messages are framed for target groups. ${ }^{12}$ Risk communication approaches are particularly problematic when the targets are adolescents. First, we actually encourage adolescents to leave the protective cocoon of childhood and to expose themselves to new risks as part of their normal maturation toward adulthood. It is neither desirable nor practical to train adolescents to be dispositionally risk-averse as a means to discourage smoking. Second, and related to the above, is the "dare to" phenomenon. Unless smoking is seen as absolutely too risky to be worth the risk, smoking can be used by adolescents prepared to take the risk as a convenient way to differentiate themselves from those too timid or too childish to take the risk. Although the "dare to" phenomenon does not require smoking as its focus, daring is arguably a significant component of overall self-esteem-who among Tobacco Control readers does not store in their personal biographies treasured memories of having toughed it out, when others didn't try, or fell by the wayside?

If emphasising the dangers of smoking to teenagers is problematic, perhaps emphasising the sheer lifestyle delights of being a non-smoker - the positive message-will work. The inherent difficulty with this marketing approach is that there is no tangible product to market. Non-smoking is an absence of smoking. How do you depict it? How do you attach valued associations to something you can't see, taste, or touch? Well-meaning attempts to depict the positive lifestyle of nonsmokers, the one you'll aspire to, tend to nauseate teenagers most at risk for smoking and may simply motivate them to differentiate themselves by the act of smoking.

A communication strategy specific to teenagers that avoids most of the problems described above involves demonisation of the tobacco industry. This has been widely used in campaigns in California and latterly in Florida, where early reports of effectiveness are encouraging. ${ }^{13}$ What is meant to motivate teenagers not to smoke is their reaction against being deceived by a self-serving tobacco industry. There is much to be said for the psychological reasoning underpinning this strategy - self-esteem would be enhanced by not smoking; rebellion against an adult authority is actually encouraged. As well as engendering outrage, the approach lends itself to humorous irony and satire which amuses as well as informs and motivates. But even this approach may be flawed. If smoking is a problem behaviour, young smokers are in a sense deviant, non-conforming, and somewhat alienated from notions of normative behaviour. It would be unfortunate if tobacco industry demonisation led to young smokers feeling they had a common cause with the industry against establishment values. This might be a particular hazard among cynical adolescents. Even if industry demonisation were initially effective, one might also ask how durable contrariness might be as a reason for not smoking. This strategy depends on maintaining the belief that to smoke would be to concede tobacco industry influence over one's behaviour. Yet it might be quite easy for a teenager to accept that the tobacco industry tries to get him or her to smoke because the industry profits and simultaneously to say: "But I smoke because I want to". Finally, because battle-scarred tobacco control advocates are so inured to the infamies of the tobacco industry, it feels good to have a platform for vilification. This justifiable feeling, however, needs to be set aside when assessing effective positioning of formal communication campaigns aimed at teenagers. (I am not, of course, suggesting that relentless exposure through litigation and news coverage of tobacco industry dirty tricks be in any way abated.)

There is clearly a strong political need for something vigorous to be seen to be done about teenage smoking, if only because tobacco control advocates have played hard on the theme that we must protect our kids from tobacco. Paradoxically, elected representatives may get most praise for campaigns their adult electors see as transparently directed at teenagers, yet I have argued here that such campaigns are likely to be the least effective, and they may even be counter-productive. Non-transparent strategies to reduce teenage smoking will need to be sold skilfully to legislators and to the public.

Despite the difficulties described above, I believe there are ways to reduce uptake of smoking among adolescents, but they are oblique and they involve behavioural change in adult smokers. First, parents and family members of pre-teenagers and teenagers need to stop smoking. It has been known for a long 
time that parental and sibling smoking is a risk factor for smoking in adolescents. ${ }^{14}$ It now seems that quitting by parents reduces the likelihood of offspring taking up smoking. ${ }^{15}$

Second, as adolescents in the age group at risk for smoking have reached the piagetian stage of formal operations, their powers of cognition are those of adults. ${ }^{16}$ Relationships between actions and consequences, including delayed consequences, can be as well understood by teenagers as by adults. At least in principle, motivational health arguments and evidence against smoking have the capacity to be received, understood, and acted upon by adolescents.

Third, on the grounds that adolescents want to be treated as grown ups, they should respond as adults to adult-focused campaigns. Indeed, this appears to have happened in the recent Australian national tobacco campaign, from which preliminary data indicate comparable responses from 15-17 year olds and 18-39 year olds, and responses suggest the adult cessation focus was more effective with teenagers than a campaign specifically targeting them. ${ }^{17}$

In conclusion, my proposition is that tobacco control specialists need to keep their nerve in the face of depressingly little improvement in teenage smoking rates and face the fact that teenage smoking is unlikely to decline substantially unless and until adult rates drop substantially. There is no basis for defeatism about adult smoking when it is recognised that quitting among smokers is a majority behaviour. By the time they reach their mid-forties, more than half of the people who have ever smoked have quit. ${ }^{12}$ These are the basic messages for parents, politicians, and the public.

Centre for Behavioural Research in Cancer,

DAVID HILL

Cancer Control Research Institute,

Anti-Cancer Council of Victoria,

1 Rathdowne Street, Carlton South,

Victoria 3053, Australia;

davidh@accv.org.au
1 Peto R. Global tobacco mortality: monitoring the growing epidemic. In: Proceedings of the tenth world conference on tobacco or health, 24-28 August 1997, Beijing, China, 1997. In press.

2 Wiencke JK, Thurston SW, Kelsey KT, et al. Early age at smoking initiation and tobacco carcinogen DNA damage in the lung. $\mathcal{F}$ Natl Cancer Inst 1999;91:614-19.

3 Australian National Health and Medical Research Council. The health effects of passive smoking. Canberra, Australia: National Health and Medical Research Council, 1997.

4 Potts RJ, Newbury CJ, Smith G, et al. Sperm chromatin damage associated with male smoking. Mutat Res 1999; 423:103-11.

5 US Department of Health and Human Services. Preventing tobacco use among young people. A report of the Surgeon General, 1994. Atlanta, Georgia: Public Health Service, Centers for Disease Control and Prevention, Office on Smoking and Health, 1994. (US Government

6 Crockett LJ, Petersen AC. Adolescent development: health risks and opportunities for health promotion. In: Millstein SG, Petersen AC, Nightingale EO, eds. Promoting the health of adolescents. New York: Oxford University Press, 1993.

7 Ingra V, Irwin CE. Theories of adolescent risk taking behaviour. In: Di Clemente RJ, Hansen WB, Ponton LE, eds. Handbook of adolescent health risk behaviour. New York: Ple-

8 Jessor R, Jessor SL. Problem behaviour and psychological development: a longitudinal study of youth. New York: Academic Press, 1997.

9 Pierce JP, Gilpin EA, Emery SL, et al. Has the California tobacco control program reduced smoking? $\mathscr{F} A M A$ 1998;280:893-9.

10 Philip Morris (Australia) Limited. Corporate Affairs Plan 1992. Document ID 2023240608/0627. www.tobacco 1992. Document ID 2023240608/0627. www.
archive.com/docarch.html (accessed 22 Jun 1999).

11 Teenage Research Unlimited. Counter-tobacco advertising - exploratory summary report. www.tobacco freekids.org (accessed 12 August 1999).

12 Hill D, Chapman S, Donovan R. The return of scare tactics. Tobacco Control 1998;7:5-8.

13 Bauer U, Johnson T, Pallentino JD, et al. Tobacco use among middle and high school students-Florida, 1998 and 1999. MMWR 1999;48:248-53.

14 US Department of Health, Education, and Welfare. Smoking and health. A report of the Surgeon General, 1979. Rockville, Maryland: Public Health Service, Office on Smoking and Health, 1979. (DHEW Publication No (PHS) 79-50066.)

15 Farkas AJ, Distefan JM, Choi WS, et al. Does parental smoking cessation discourage adolescent smoking? Prev Med 1999;28:213-18.

16 Piaget J, Inhelder B. The psychology of the child. New York: Basic Books, 1969.

17 Wakefield M, Miller C, Roberts L. Comparison of the National Tobacco Campaign with a youth targeted South Australian campaign. In: Hassard K, ed. Australia's national tobacco campaign evaluation report no 1. Canberra, Australia: Commonwealth Department of Health and Aged Care, 1999. 